\title{
Steatosis, Glycation and Liver Fibrosis in Patients with Diabetes \\ Marty $\mathbf{M}^{1,2 *}$, Hiriart $\mathrm{JB}^{2,3}$, Vergniol $\mathrm{J}^{3}$, Foucher $\mathrm{J}^{3}$, De Ledinghen $\mathrm{V}^{2,3}$, Gin $\mathrm{H}^{1,2}$ and Rigalleau $\mathbf{V}^{1,2}$
}

${ }^{1}$ Nutrition-Diabétologie, Bordeaux hospital, F-33600 Pessac, France

${ }^{2}$ Université Bordeaux, F-33000 Bordeaux, France

${ }^{3}$ Hepatogastroenterologie Bordeaux Hospital, F-33600 Pessac, France

\begin{abstract}
Introduction: Non Alcoholic Fatty Liver Disease (NAFLD) is frequent and progresses to fibrosis among patients with diabetes. The roles of hepatic steatosis and of the accumulation of Advanced Glycation Endproducts (AGEs) can now be analyzed by new non-invasive methods.

Patients and methods: Among hospitalized patients with diabetes, we assessed liver fibrosis by liver stiffness measurement (LSM), steatosis by the attenuation coefficient of an ultrasonic wave (CAP) and AGE accumulation by skin autofluorescence (sAF). The patients with severe fibrosis were compared to the others by ANOVA and Chi-2, and the relations between fibrosis, steatosis, and skin $\mathrm{AF}$ were studied by regression analysis.

Results: 178 patients were included: $60 \%$ male, age $59 \pm 11$ years, BMI $31 \pm 6 \mathrm{~kg} / \mathrm{m}^{2}, 79 \%$ with Type 2 Diabetes (T2D), poorly controlled (HbA1C $9.0 \pm 2.4 \%$ ). SAF were available in all patients, LSM in 139 and CAP in 93 subjects. Severe fibrosis $(\mathrm{LSM}>8.7 \mathrm{kPa})$ was evidenced in $32(23 \%)$ patients, mainly $\mathrm{T} 2 \mathrm{D}(\mathrm{n}=31 / 32)$, with higher BMI and waist circumference $(p<0.0001)$. They had higher CAP: $319 \pm 53 \mathrm{~dB} / \mathrm{m}$ (No fibrosis: $268 \pm 59, p<0.005$ ), whereas their SAF did not differ. LSM was correlated to the CAP $(r=0.40, p<0.0001)$ and the waist circumference $(r=0.46$, $p<0.0001)$, but not to SAF. CAP was related to waist circumference and triglycerides level $(r=0.70$ in multivariate analysis).
\end{abstract}

Conclusion: More steatosis and similar skin autofluorescence in patients with diabetes and severe liver fibrosis support that steatosis promotes fibrosis, and suggests that AGEs do not accelerate this progression.

Keywords: Non alcoholic fatty liver disease; Diabetes; Fibrosis; Steatosis; Advanced glycation endproducts; Skin autofluorescence

\begin{abstract}
Abbreviations: AGEs: Advanced Glycation End Products; AER: Albumin Excretion Rate; ALAT: Alanine Aminotransferase; ASAT: Aspartate Aminotransferase; AU: Arbitrary Unit; BMI: Body Mass Index; CAP: Controlled Attenuation Parameter; GGT: Gamma Glutamyl Transferase; GFR: Glomerular Filtration Rate; HbA1C: Glycosylated Hemoglobin A1C; HBs Ag: Hepatitis B Antigen; HCV Ab: Hepatitis C Antibody; HDL-cholesterol: High-Density Level Cholesterol; HIV Ab: Human Immunodeficient Virus Antibody; kPa: Kilopascals; IDF: International Diabetes Federation; IQR: Interquartile Range; LDL-cholesterol: Low-Density Level Cholesterol; LSM: Liver Stiffness Measurement; NAFLD: Nonalcoholic Fatty Liver Disease; PAL: Phosphatase Alcaline; sAF: Skin Autofluorescence; T2D: Type 2 Diabetes; T1D: Type 1 Diabetes; TG: Triglycerides; VCTETM ${ }^{*}$ : Vibration-Controlled Elastography
\end{abstract}

\section{Introduction}

Non Alcoholic Fatty Liver Diseases (NAFLD) causes serious hepatic damage and can lead to fibrosis, cirrhosis and liver cancer [1]. Their natural history includes two phases: first the accumulation of triglycerides due to insulin resistance makes a vulnerable steatotic liver, and then a second hit, involving oxidative stress, leads to inflammation and fibrosis [2] . These events are not clinically apparent, and diagnosis is delayed. NAFLD is a cause of "cryptogenetic" cirrhosis [3]. A direct histological follow-up is rarely performed because the liver biopsy is an invasive procedure, indicated only when advanced lesions are suspected, whereas a simple steatosis is benign [4]. Whether triglycerides by themselves are toxic for the liver is even uncertain, some reports suggest that their accumulation may be a mechanism of defense against liver injury $[5,6]$. Noninvasive procedures of evaluation of liver fibrosis and steatosis, by Fibroscan (Liver Stiffness Measurement LSM and Controlled Attenuation Parameter CAP) seem adapted to study early stages of NAFLD in high risk populations, like patients with diabetes [7]. Are the levels of steatosis high in patients with diabetes and hepatic fibrosis?

NAFLD are especially frequent among patients with diabetes [8]; mainly Type 2, but Type 1 Diabetes is also concerned [9]. They progress more to liver fibrosis, rates of severe fibrosis detected by Fibroscan are as high as $15 \%$ in patients hospitalized for diabetes $[10,11]$. The mechanism for the acceleration of NAFLD by diabetes is unknown, the role of Advanced Glycation Endproducts (AGEs) is suspected because they activate hepatic stellate cells [12]. The accumulation of AGEs in tissues can now be estimated by the measurement of the skin autofluorescence (sAF) [13]. sAF is high in poorly controlled diabetes [14], and in non-diabetic patients with cirrhosis [15]. Is sAF high in patients with diabetes and hepatic fibrosis?

In 178 patients hospitalized for their poorly controlled diabetes, we measured the $\mathrm{SAF}$, and we proposed a non-invasive screening for NAFLD; liver fibrosis was assessed by the LSM, and steatosis by the CAP. We compared the levels of sAF and hepatic steatosis according

*Corresponding author: Marie Marty, Nutrition-Diabétologie, Hôpital HautLévêque, Avenue de Magellan, 33600 Pessac, France, Tel: 33557656078; Fax 33557656079; E-mail: marie.marty@chu-bordeaux.fr

Received November 01, 2015; Accepted December 24, 2015; Published December 30, 2015

Citation: Marty M, Hiriart JB, Vergniol J, Foucher J, De Ledinghen V, et al. (2015) Steatosis, Glycation and Liver Fibrosis in Patients with Diabetes. J Diabetes Metab 6: 633. doi:10.4172/2155-6156.1000633

Copyright: (c) 2015 Marty M, et al. This is an open-access article distributed unde the terms of the Creative Commons Attribution License, which permits unrestricted use, distribution, and reproduction in any medium, provided the original author and source are credited. 
to the presence of severe liver fibrosis, and we searched for a relation between sAF, steatosis, and liver fibrosis.

\section{Patients and Methods}

\section{Patients}

From August 2010 to June 2013, we enrolled diabetic patients hospitalized at the Diabetology unit of Bordeaux's University Hospital. We measured the sAF and we proposed a non-invasive screening for NAFLD. Patients with active sepsis or ongoing foot ulcer were excluded to avoid their movement to the centre for non-invasive screening of fibrosis that was located three floors below the Diabetology Hospitalization Unit. Patients with diabetes secondary to chronic pancreatitis or haemochromatosis were excluded. Dark skinned patients were excluded because sAF measurements are not valid in these cases. None of the patients had viral (HBs Ag, HCV Ab and HIV Ab negative), autoimmune or genetically induced (haemochromatosis, Wilson's disease or alpha 1-antitrypsin deficiency) liver diseases. Alcohol use was evaluated. For all patients, clinical parameters, blood sample, sAF, LSM and CAP assessment were performed during the same hospitalization. The study protocol was conformed to the ethical guidelines of the 1975 Declaration of Helsinski and patients were included after written informed consent was obtained.

\section{Clinical and biological parameters}

Clinical parameters included type and duration of diabetes, weight, height, waist circumference, body mass index (BMI), high blood pressure, alcohol and tobacco use. Metabolic syndrome was defined as follows waist circumference $>94 \mathrm{~cm}$ for men and $80 \mathrm{~cm}$ for women, antihypertensive treatment or blood pressure $>130 / 85 \mathrm{mmHg}$, type 1 or type 2 diabetes, triglycerides $>1.6 \mathrm{mmol} \mathrm{L}^{-1}$ and HDL-cholesterol $<1.04 \mathrm{mmol} \mathrm{L}^{-1}$ for men and $<1.29 \mathrm{mmol} \mathrm{L}^{-1}$ for women, according to the IDF criteria [16].

Biological parameters included fasting glucose, glycated hemoglobin, total cholesterol, HDL cholesterol, triglycerides, creatinin, albumin excretion rate, aspartate aminotransferase (AST), alanine aminotransferase (ALT), and gamma glutamyltransferase (GGT). Blood sample analysis was centralized in the laboratory of our hospital.

\section{Skin autofluorescence (sAF)}

sAF was measured with an AGE-Reader (DiagnOptics BV, Groningen, The Netherlands). The AGE-Reader illuminates approximately $1 \mathrm{~cm}^{2}$ of skin (guarded against surrounding light) with an excitation light source of 300-420 nm (peak excitation $\approx 350 \mathrm{~nm}$ ). Emission light and reflected excitation light from the skin is measured with a spectrometer in the $300-600 \mathrm{~nm}$ range, using a glass fiber. sAF was computed by dividing the average light intensity of the emission spectrum $420-600 \mathrm{~nm}$ by the average light intensity of the excitation spectrum $300-420 \mathrm{~nm}$, multiplied by 100 and expressed in arbitrary units (AU).

sAF was assessed at the volar side of the forearm, $10 \mathrm{~cm}$ below the elbow fold. The accumulation of AGEs was estimated with sAF measured by the AGE Reader (DiagnOpticsTechnologies B.V., Groningen, Netherlands) and expressed in AU [13]. The value of sAF was demonstrated by its correlation with the cutaneous concentrations of pentosidine $(\mathrm{r}=0.55)$ and Carboxymethyl-lysine $(\mathrm{r}=0.50)$ in diabetic and hemodialized patients [13]. The measurement was performed in triplicate at the skin site on the forearm. Subjects with Fitzpatrick skin phototype $\mathrm{V}$ and VI were not evaluated due to their skin pigmentation with ultraviolet reflectance $<10 \%$.
References of normal sAF depend on age, as reported by Koetsier et al. [18].

Theoretical skin autofluorescence $=0.024($ age $)+0.83$, age in years.

The reproducibility is indicated by a mean coefficient of variation relative error of $5 \%$ [17].

\section{Liver stiffness measurement (LSM)}

LSM was obtained using signals acquired by the FibroScan ${ }^{\circ}$ (Echosens, Paris) M probe based on vibration-controlled elastography $\left(\right.$ VCTETM $\left.^{*}\right)$. LSM was performed with the patient lying in dorsal decubitus with the right arm in maximal abduction, on the right lobe of the liver, through intercostal spaces. The operator assisted by a timemotion ultrasound image, located a liver portion distance of large vascular structures. When the target area had been located, he pressed the $\mathrm{M}$ probe button to start the measurements. The final liver stiffness result was the median value of ten measurements performed between 25 and $65 \mathrm{~mm}$ depth and was expressed in $\mathrm{kPa}$. Only procedures with ten valid shots and interquantile range (IQR) inferior to $30 \%$ were considered reliable. LSM was performed by the same specialized nurses.

According to cut-offs published in NAFLD patients, severe fibrosis was predicted when liver stiffness was greater than $8.7 \mathrm{kPa}$ [18]. The threshold used ( $8.7 \mathrm{Kpa}$ ) for the diagnosis of severe fibrosis was the cut off value determined in Wong's study in 2010 with a sensivity of $83.9 \%$, a specificity of $83.2 \%$ and a negative predictive value of $94.6 \%$ for the diagnostic of advanced fibrosis. This cut off value was interesting for two reasons: firstly the CIF (Fibrosis Investigation Center of Haut Leveque Hospital) participated in this bicentric multinational study and secondly this study was targeted only on patients without any hepatic disease none other than NAFLD [19].

\section{Controlled attenuation parameter (CAP)}

Controlled attenuation parameter has been designed to measure liver ultrasonic attenuation (go and return path) at $3.5 \mathrm{MHz}$ on the signals acquired by the FibroScan ${ }^{\circledR}$ [20]. CAP was computed with the same signals as the one used to measure liver stiffness and was only calculated when the LSM was valid. Therefore both stiffness and CAP were obtained simultaneously in the same volume of liver parenchyma (namely between 25 and $65 \mathrm{~mm}$ ). The final CAP value was the median value of the ten individual measurements and was expressed in $\mathrm{dB} / \mathrm{m}$.

Steatosis was predicted as severe when $\mathrm{CAP}>300 \mathrm{~dB} / \mathrm{m}$. This cut value was determined in the study conducted by de Ledeinghen at the CIF and published in 2012, for which the sensitivity is $\geq 90 \%$ [7].

\section{Statistical analysis}

Statistical analysis was performed with SPSS software. Variables were expressed as mean \pm standard deviations. Continuous variables were compared by ANOVA. Discontinuous variables were compared by the Chi-2. The relations of liver fibrosis and steatosis with potential explicative variables were analyzed by Multivariate regression, step by step. Significance was defined by a $\mathrm{p}<0.05(\mathrm{Chi}-2)$ and $\mathrm{p}<0.01$ (ANOVA).

\section{Results}

\section{Characteristics of the population (Table 1)}

One hundred and seventy eight patients were included and described in Table 1. Their skin autofluorescence was $2.42 \pm 0.64$ A.U, 


\begin{tabular}{|c|c|}
\hline \multicolumn{2}{|c|}{ Population } \\
\hline Number (\%) & 178 \\
\hline Gender: males (\%) & $106(60 \%)$ \\
\hline Age (years) & $59 \pm 11$ \\
\hline BMI $\left(\mathrm{kg} / \mathrm{m}^{2}\right)$ & $31 \pm 6$ \\
\hline Waist circumference $(\mathrm{cm})$ & $105 \pm 16$ \\
\hline High blood pressure (\%) & $140(79 \%)$ \\
\hline Type 2 diabetes (\%) & $141(79.2 \%)$ \\
\hline Alcohol (drinks/week) & $9 \pm 15$ \\
\hline Tobacco (pack-years) & $19 \pm 27$ \\
\hline Fasting glucose (mmol/L) & $8.52 \pm 3.20$ \\
\hline $\mathrm{HbA1C}(\%)$ & $9.0 \pm 2.4$ \\
\hline Cholesterol (mmol/L) & $4.95 \pm 1.64$ \\
\hline $\mathrm{TG}(\mathrm{mmol} / \mathrm{L})$ & $2.08 \pm 2.12$ \\
\hline $\mathrm{HDL}-\mathrm{C}(\mathrm{mmol} / \mathrm{L})$ & $1.22 \pm 0.36$ \\
\hline Estimated GFR $\left(\mathrm{ml} / \mathrm{min} / 1,73 \mathrm{~m}^{2}\right)$ & $86 \pm 23$ \\
\hline $\mathrm{AER} / 24 \mathrm{H}(\mathrm{mg} / 24 \mathrm{H})$ & $148 \pm 394$ \\
\hline ALAT $\left(\mathrm{x} \mathrm{N}^{\mathrm{a}}\right)$ & $1.00 \pm 0.85$ \\
\hline ASAT $\left(\mathrm{xN}^{\mathrm{a}}\right)$ & $0.94 \pm 0.84$ \\
\hline GGT $\left(x^{N}{ }^{a}\right)$ & $2.05 \pm 5.21$ \\
\hline PAL $\left(x^{N}\right.$ a) & $0.62 \pm 0.25$ \\
\hline SAF (A.U.) & $2.42 \pm 0.64$ \\
\hline
\end{tabular}

Results are given as mean \pm standard deviation or number of patients $(\%)$. ${ }^{a} \mathrm{~N}$ refers to the normal upper limit of reference range and $\mathrm{x}$ is a multiple of $\mathrm{N}$ ${ }^{\mathrm{b}}$ The CKD-EPI equation expressed as a single equation, is GFR $=141 \mathrm{X}$ $\min (\mathrm{Scr} / \mathrm{K}, 1)^{\alpha} \mathrm{X} \max (\mathrm{Scr} / \mathrm{K}, 1)^{-1.209} \times 0.993^{\mathrm{Age}} \times 1.018$ [if female] X 1.159 [if black] where $\mathrm{Scr}$ is serum creatinine, $\mathrm{k}$ is 0.7 for females and 0.9 for males, $\alpha$ is -0.329 for females and 60.411 for males, min indicates the minimum of Scr/K or 1 , and max indicates the maximum of Scr/K or 1 Normal eGFR is $90 \mathrm{~mL} / \mathrm{min} / 1.73 \mathrm{~m}^{2}$.

Table 1: Patients characteristics of the study.

related to age, micro albuminuria and tobacco use. The patients with type 1 diabetes were younger, had lower BMI and waist circumference and their level of transaminases were lower.

\section{Liver fibrosis}

The measurement of liver stiffness was successfull in 139 patients: 107 T2D and 32 T1D. Thirty two patients (23\%) had severe fibrosis according to a liver stiffness $>8.7 \mathrm{kPa}$, their characteristics are summarized in the Table 2: they were more T2D, with higher waist and BMI. Their CAP was $+19 \%$ higher $(\mathrm{p}=0.002)$ than for subjects without severe fibrosis, whereas their skin autofluorescence did not differ.

Liver stiffness was related to age higher than fifty years old, BMI, waist circumference, alcohol and tobacco use, and serum creatinine by univariate regression analysis. By multivariate analysis, the relations with waist circumference, alcohol consumption and serum creatinine were still significant Table 3 .

The liver stiffness did not relate to the $\mathrm{sAF}(\mathrm{r}=0.030, \mathrm{p}=0.774)$.

\section{Liver Steatosis}

The measurement of the CAP was successfull in 93 patients: 64 T2D and 31 T1D. Forty one percent of the subjects had severe steatosis $(\mathrm{CAP}>300 \mathrm{~dB} / \mathrm{m})$. Liver steatosis was related to age, $\mathrm{BMI}$, waist circumference, triglycerides and HDL-cholesterol by univariate regression analysis. By multivariate analysis, the relations with waist circumference and serum triglycerides were still significant (Table 4).

The CAP was not related to the skin autofluorescence, whereas it was correlated to liver stiffness as shown on the Figure $1(\mathrm{r}=0.40, \mathrm{p}<0.001)$.

\section{Discussion}

The high $23 \%$ rate or liver fibrosis we found could be expected. NAFLD are twice more of frequent among subjects with diabetes [20,21]. Studies employing non-invasive methods reported severe fibrosis in $5.6 \%$ of outpatients using fibrotest [22] and up to $15 \%$ in hospitalized patients in our previous study using LSM [11]. The rate of severe fibrosis confirmed by biopsies reached 35\% in another study with Type 2 Diabetes patients [23]. Our main findings are that these fibrosis associate with hepatic steatosis, and not with the accumulation of AGEs evaluated by sAF.

Although not reported yet in diabetes, the relation between fibrosis and steatosis could be expected: steatosis is thought to preceed inflammation and fibrosis in the natural history of NAFLD [2]. Noninvasive studies are however crucial to better assess this history: simple steatosis seems a benign condition, that exceptionally $(<1 \%)$ progresses to cirrhosis [24]. Two experimental studies in animals have suggested that steatosis may protect rather than promote inflammation and fibrosis. Listenberg et al have reported that the incorporation of saturated fatty acids in the hepatic TG pool prevented their proapoptotic effects [5]. Yamagushi et al. [7] found more inflammation, necrosis and fibrosis in mice whose DGAT inhibition reduced Hepatic TG synthesis [6]. If TG efficiently protected the liver from fibrosis, we should have found an inverse relation between steatosis and fibrosis. Of note, the relations we found between fibrosis and age $(\mathrm{p}<0.01)$ [25-27] T2D $(\mathrm{p}<0.05)[25,26]$, waist circumference $(\mathrm{p}<0.01)[25]$ and tobacco

\begin{tabular}{|c|c|c|c|}
\hline & LSM $>8.7 \mathrm{kPa}$ & LSM $\leq 8.7 \mathrm{kPa}$ & $\mathbf{p}$ \\
\hline Number (\%) & $32(23 \%)$ & $107(77 \%)$ & \\
\hline Liver stiffness $(\mathrm{kPa})$ & $13.4 \pm 4.6$ & $5.2 \pm 1.3$ & 0.000 \\
\hline Type 2 diabetes (\%) & $31(96.8 \%)$ & $77(71.3 \%)$ & 0.002 \\
\hline Waist circumference $(\mathrm{cm})$ & $113 \pm 12$ & $99 \pm 14$ & 0.000 \\
\hline BMI $\left(\mathrm{kg} / \mathrm{m}^{2}\right)$ & $33.8 \pm 4$ & $28.8 \pm 4.7$ & 0.000 \\
\hline Alcohol (drinks/week) & $12.9 \pm 20.9$ & $9.4 \pm 14.5$ & NS \\
\hline Tobacco (pack-years) & $26.6 \pm 30.6$ & $15.5 \pm 19.6$ & 0.017 \\
\hline $\mathrm{HbA1C}(\%)$ & $8.6 \pm 3.5$ & $9.1 \pm 2.2$ & NS \\
\hline $\operatorname{ALAT}\left(x^{N}\right.$ a) & $1.92 \pm 1.30$ & $0.83 \pm 0.58$ & 0.000 \\
\hline $\operatorname{ASAT}\left(\mathrm{xN}^{\mathrm{a}}\right)$ & $1.82 \pm 1.54$ & $0.74 \pm 0.38$ & 0.000 \\
\hline GGT ( $\left.\mathrm{xN}^{\mathrm{a}}\right)$ & $3.31 \pm 3.14$ & $1.88 \pm 6.36$ & NS \\
\hline PAL $\left(x^{a}\right)$ & $0.61 \pm 0.20$ & $0.59 \pm 0.23$ & NS \\
\hline Serum creatinine $(\mu \mathrm{mol} / \mathrm{L})$ & $73 \pm 21$ & $82 \pm 36$ & NS \\
\hline Estimated GFR $\left(\mathrm{ml} / \mathrm{min} / 1.73 \mathrm{~m}^{2}\right)^{\mathrm{b}}$ & $88.6 \pm 19.4$ & $87.2 \pm 23.9$ & NS \\
\hline $\operatorname{AER}(\mathrm{mg} / 24 \mathrm{H})$ & $121 \pm 230$ & $149 \pm 442$ & NS \\
\hline $\mathrm{CAP}(\mathrm{dB} / \mathrm{m})$ & $319 \pm 53$ & $268 \pm 59$ & 0.002 \\
\hline sAF (A.U.) & $2.45 \pm 0.61$ & $2.35 \pm 0.65$ & NS \\
\hline
\end{tabular}

Results are given as mean \pm standard deviation or number of patients (\%). a $\mathbf{N}$ refers to the normal upper limit of reference range and $\mathrm{x}$ is a multiple of $\mathbf{N}$ b The CKD-EPI equation expressed as a single equation, is GFR $=141 \mathrm{X}$ $\min (\mathrm{Scr} / \mathrm{K}, 1)^{\alpha} \mathrm{X} \max (\mathrm{Scr} / \mathrm{K}, 1)^{-1.209} \mathrm{X} 0.993^{\mathrm{Age}} \mathrm{X} 1.018$ [if female] X 1.159 [if black] where $\mathrm{Scr}$ is serum creatinine, $\mathrm{k}$ is 0.7 for females and 0.9 for males, $\alpha$ is -0.329 for females and 60.411 for males, min indicates the minimum of Scr/k or 1 , and max indicates the maximum of Scr/K or 1 . Normal eGFR is $90 \mathrm{~mL} / \mathrm{min} / 1.73 \mathrm{~m}^{2}$.

Table 2: Clinical and biological characteristics of the subgroup of patients with severe fibrosis (LSM >8.7 $\mathrm{kPa}$ ) compared to the patients with $\mathrm{LSM} \leq 8.7 \mathrm{kPa}$ Continuous variables were compared by ANOVA and significance was defined by a $p<0.01$. Discontinuous variables were compared by the Chi- 2 and significance was defined by $p<0.05$. 


\begin{tabular}{|c|c|c|c|c|c|c|}
\hline \multirow{2}{*}{ LSM } & \multicolumn{3}{|c|}{$\begin{array}{c}\text { Univariate regression } \\
\text { analysis }\end{array}$} & \multicolumn{3}{c|}{$\begin{array}{c}\text { Multivariate regression } \\
\text { analysis }\end{array}$} \\
\cline { 2 - 7 } & $\boldsymbol{\beta}$ & $\mathbf{9 5 \%} \mathbf{~ C l}$ & $\mathbf{p}$ & $\boldsymbol{\beta}$ & $\mathbf{9 5 \%} \mathbf{~ C l}$ & $\mathbf{p}$ \\
\hline Age > 50 & 0.212 & {$[0.495 ; 3.962]$} & 0.012 & - & - & - \\
\hline BMI & 0.440 & {$[0.240 ; 0.491]$} & 0.000 & - & - & - \\
\hline $\begin{array}{c}\text { Waist } \\
\text { circumference }\end{array}$ & 0.468 & {$[0.090 ; 0.174]$} & 0.000 & 0.46 & {$[0.089 ; 0.171]$} & 0.000 \\
\hline Alcohol & 0.237 & {$[0.019 ; 0.105]$} & 0.005 & 0.193 & {$[0.013 ; 0.088]$} & 0.009 \\
\hline Tobacco & 0.267 & {$[0.019 ; 0.080]$} & 0.001 & - & - & - \\
\hline Serum creatinin & -0.171 & {$[-0.42 ;-0.001]$} & 0.044 & -0.21 & {$[-0.044 ;-0.008]$} & 0.004 \\
\hline
\end{tabular}

Continuous variables were compared by ANOVA and significance was defined by a $p<0.01$. Discontinuous variables were compared by the Chi- 2 and significance was defined by $p<0.05$

Table 3: Associations between LSM and characteristics of the diabetics patients, univariate and multivariate regression analysis $(\mathrm{N}=139)$.

\begin{tabular}{|c|c|c|c|c|c|c|}
\hline \multirow{2}{*}{ CAP } & \multicolumn{3}{|c|}{$\begin{array}{c}\text { Univariate regression } \\
\text { analysis }\end{array}$} & \multicolumn{3}{c|}{$\begin{array}{c}\text { Multivariate regression } \\
\text { analysis }\end{array}$} \\
\cline { 2 - 7 } & $\boldsymbol{\beta}$ & $\mathbf{9 5 \%} \mathbf{~ C l}$ & $\mathbf{p}$ & $\boldsymbol{\beta}$ & $\mathbf{9 5 \%} \mathbf{~ C l}$ & $\mathbf{p}$ \\
\hline Age $>50$ & 0.301 & {$[14.22 ; 69.36]$} & 0.003 & - & - & - \\
\hline BMI & 0.553 & {$[4.790 ; 9.177]$} & 0.000 & - & - & - \\
\hline $\begin{array}{c}\text { Waist } \\
\text { circumference }\end{array}$ & 0.641 & {$[1.833 ; 3.051]$} & 0.000 & 0.566 & {$[1.543 ; 2.703]$} & 0.000 \\
\hline TG & 0.453 & {$[13.36 ; 32.07]$} & 0.000 & 0.296 & {$[7.059 ; 22.579]$} & 0.009 \\
\hline HDL-C & -0.379 & {$[-87.95 ;-28.48]$} & 0.000 & - & - & - \\
\hline
\end{tabular}

Continuous variables were compared by ANOVA and significance was defined by a $p<0.01$. Discontinuous variables were compared by the Chi-2 and significance was defined by a $p<0.05$

Table 4: Associations between CAP and characteristics of the diabetics patients, univariate and multivariate regression analysis $(\mathrm{N}=93)$.

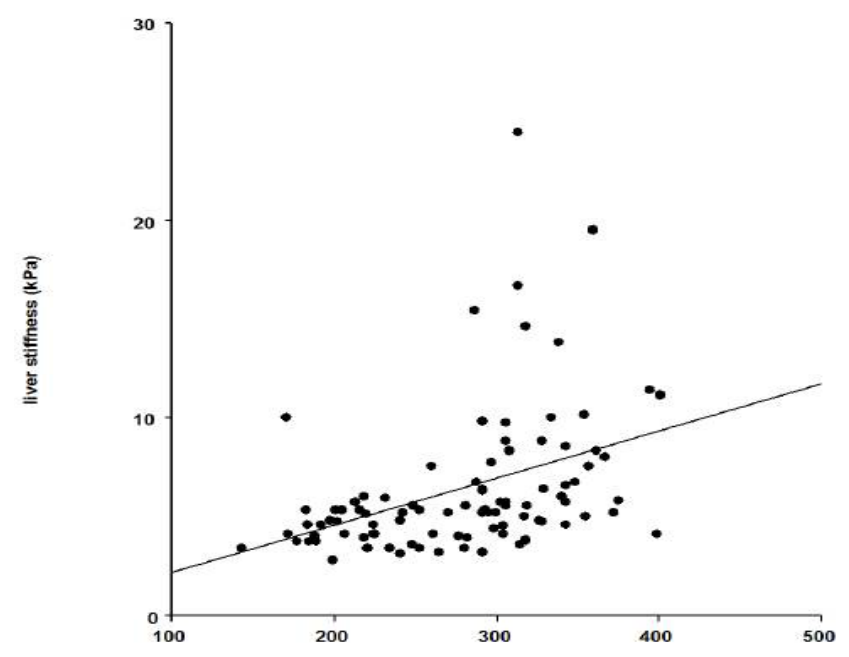

Controlled attenuation parameter $(\mathrm{dB} / \mathrm{m})$

Figure 1: LSM values ( $y$ axis plotted against the values of CAP ( $x$ axis), $r=0.40, p<0.001$

$(\mathrm{p}<0.05)[25]$ are well accorded to the literature. Forty-one percent of our patients had severe steatosis according to a CAP $>300$. The strong relation of CAP with waist circumference $(\mathrm{p}<0.01)$ and TG $(\mathrm{p}<0.01)$ confirms its dependency on insulin resistance $[27,28]$.

On the other hand, the absence of relation between liver fibrosis and skin autofluorescence was unexpected. The autofluorescence is a reliable marker of the concentration of AGEs in the skin [13], its levels are high in patients with other diabetic complications [14], that relate on organ fibrosis in some cases like nephropathy. AGEs are thought to play a role in the initial steps of liver inflammation [12], and we have previously reported high autofluorescence in non-diabetic patients with cirrhosis [15]. The limited number of patients does not seem a good explanation for our negative result: on this limited population we detected the expected relation between steatosis and fibrosis. The previously reported relations between skin autofluorescence and age $(\mathrm{p}<0.01)$ $[13,17,27]$, microalbuminuria $(\mathrm{p}<0.01)[29]$ and tobacco $(\mathrm{p}<0.05)[17]$ were also present in our patients. Liver-toxic glyceraldehyde-derived AGEs [30] are increased in the serum of progressive Non Alcoholic Steato Hepatite vs simple steatosis [31], but may not be detected by autofluorescence, or may not accumulate in the skin like in the liver. Our result do not argue for an important deleterious effect of AGEs in NAFLD, but further work on this hypothesis seems necessary, due to the limitations of our study.

The first limit of our study is that our study population is not representative of the whole population of diabetics: they were poorly controlled with a $\mathrm{HbA1C}$ of $9.0 \pm 2.4 \%$, reason for their hospitalization. The screening in hospitalized patients led to a high proportion of T1D, but they should not be excluded from studies on NAFLD, indeed quite frequent in T1D [9,32]. The second limitation is the lack of histological confirmation of our results; the gold standard remains the liver biopsy. It was impossible to perform a liver biopsy in all patients without presumed notion of liver disease. However, the diagnostic performances of Fibroscan and more recently that of CAP have been validated in a number of studies both in terms of positive diagnosis and in terms of severity $[7,33,34]$.The high diagnostic accuracy of CAP has been demonstrated also in non-populations [35]. The third limitation is our failure rate of Fibroscan of $22 \%$, higher than the $15 \%$ usually found in the literature, due to the high mean BMI of our patients was $31 \pm 6 \mathrm{~kg} / \mathrm{m}^{2}$. Besides the failure rate in T1D patients whose average BMI was $27 \pm 6 \mathrm{~kg} / \mathrm{m}^{2}$ was $13 \%$ while that of T2DM whose average BMI was $32 \pm 5 \mathrm{~kg} / \mathrm{m}^{2}$ was $24 \%$. Now, we have at our disposal the XL probe to measure the LSM and the CAP when the BMI is too high, this will reduce the failure rate for further studies.

Despite these limitations, our study is the first to simultaneously assess liver steatosis, liver stiffness, and skin autofluorescence in patients with diabetes, providing new informations: high rates of severe fibrosis related to high rates of severe steatosis associated to hypertriglyceridemia, waist circumference, and no relation with the skin autofluorescence. Chronic exposure to AGE estimated by sAF does not seem to take part in neither the onset nor the severity of hepatic fibrosis in our study. We already know that there are different AGE and they do not have the same toxicity [30]. Liver biomarkers are needed to support the hypothesis that AGE are or are not involved in hepatic fibrosis.

\section{References}

1. Vernon G, Baranova A, Younossi ZM (2011) Systematic review: the epidemiology and natural history of non-alcoholic fatty liver disease and nonalcoholic steatohepatitis in adults. Aliment Pharmacol Ther 34: 274-285.

2. Paradis V, Bedossa $P(2008)$ Definition and natural history of metabolic steatosis: histology and cellular aspects. Diabetes Metab 34: 638-642.

3. Yatsuji S, Hashimoto E, Tobari M, Taniai M, Tokushige K, et al. (2009) Clinical features and outcomes of cirrhosis due to non-alcoholic steatohepatitis compared with cirrhosis caused by chronic hepatitis C. J Gastroenterol Hepatol 24: 248-254.

4. Nakamura A, Osonoi T, Terauchi Y (2010) Relationship between urinary sodium excretion and pioglitazone-induced edema. J Diabetes Investig 1: 208-211. 
Citation: Marty M, Hiriart JB, Vergniol J, Foucher J, De Ledinghen V, et al. (2015) Steatosis, Glycation and Liver Fibrosis in Patients with Diabetes. J Diabetes Metab 6: 633. doi:10.4172/2155-6156.1000633

Page 5 of 5

5. Teli MR, James OF, Burt AD, Bennett MK, Day CP (1995) The natural history of nonalcoholic fatty liver: a follow-up study. Hepatology 22: 1714-1719.

6. Listenberger LL, Han X, Lewis SE, Cases S, Farese RV Jr, et al. (2003) Triglyceride accumulation protects against fatty acid-induced lipotoxicity. Proc Natl Acad Sci U S A 100: 3077-3082.

7. Yamaguchi K, Yang L, McCall S, Huang J, Yu XX, et al. (2007) Inhibiting triglyceride synthesis improves hepatic steatosis but exacerbates liver damage and fibrosis in obese mice with nonalcoholic steatohepatitis. Hepatology 45 1366-1374.

8. de Lédinghen V, Vergniol J, Foucher J, Merrouche W, le Bail B (2012) Noninvasive diagnosis of liver steatosis using controlled attenuation parameter (CAP) and transient elastography. Liver Int 32: 911-918.

9. Porepa L, Ray JG, Sanchez-Romeu P, Booth GL (2010) Newly diagnosed diabetes mellitus as a risk factor for serious liver disease. CMAJ 182: E526-531.

10. Targher G, Bertolini L, Chonchol M, Rodella S, Zoppini G, et al. (2010) Nonalcoholic fatty liver disease is independently associated with an increased prevalence of chronic kidney disease and retinopathy in type 1 diabetic patients. Diabetologia 53: 1341-1348.

11. Younossi ZM, Gramlich T, Matteoni CA, Boparai N, McCullough AJ (2004) Nonalcoholic fatty liver disease in patients with type 2 diabetes. Clin Gastroenterol Hepatol 2: 262-265.

12. de Lédinghen V, Vergniol J, Gonzalez C, Foucher J, Maury E, et al. (2012) Screening for liver fibrosis by using FibroScan $(\circledR)$ and FibroTest in patients with diabetes. Dig Liver Dis 44: 413-418.

13. Iwamoto K, Kanno K, Hyogo H, Yamagishi S, Takeuchi M, et al. (2008) Advanced glycation end products enhance the proliferation and activation of hepatic stellate cells. J Gastroenterol 43: 298-304.

14. Meerwaldt R, Graaff R, Oomen PH, Links TP, Jager JJ, et al. (2004) Simple non-invasive assessment of advanced glycation endproduct accumulation Diabetologia 47: 1324-1330.

15. Genevieve M, Vivot A, Gonzalez C, Raffaitin C, Barberger-Gateau P, et al (2013) Skin autofluorescence is associated with past glycaemic control and complications in type 1 diabetes mellitus. Diabetes Metab 39: 349-354.

16. Maury E, Vergniol J, Ledinghen Vd, Rigalleau V (2011) Skin autofluorescence is high in patients with cirrhosis - further arguing for the implication of Advanced Glycation End products. J Hepatol 54: 1079-1080.

17. IDF Worldwide Definition of the Metabolic Syndrome (2015) Internationa Diabetes Federation.

18. Koetsier M, Lutgers HL, de Jonge C, Links TP, Smit AJ, et al. (2010) Reference values of skin autofluorescence. Diabetes Technol Ther 12: 399-403.

19. Wong VW-S, Chan HL-Y (2010) Transient elastography. J Gastroenterol Hepatol 25:1726-1731.

20. Wong VW-S, Vergniol J, Wong GL-H, Foucher J, Chan HL-Y, Le Bail B, et al (2010) Diagnosis of fibrosis and cirrhosis using liver stiffness measurement in nonalcoholic fatty liver disease. Hepatol Baltim Md 51: 454-462.

21. Sasso M, Tengher-Barna I, Ziol M, Miette V, Fournier C, et al. (2012) Novel controlled attenuation parameter for noninvasive assessment of steatosis using Fibroscan(囚): validation in chronic hepatitis C. J Viral Hepat 19: 244-253.

22. Tai FWD, Syn WK, Alazawi W (2015) Practical approach to non-alcoholic fatty liver disease in patients with diabetes. Diabet Med J Br Diabet Assoc.

23. Jacqueminet S, Lebray $P$, Morra R, Munteanu M, Devers L, et al. (2008) Screening for liver fibrosis by using a noninvasive biomarker in patients with diabetes. Clin Gastroenterol Hepatol 6: 828-831.

24. Casey SP, Kemp WW, McLean CA, Topliss DJ, Adams LA, et al. (2012) A prospective evaluation of the role of transient elastography for the detection of hepatic fibrosis in type 2 diabetes without overt liver disease. Scand $J$ Gastroenterol 47: 836-841.

25. Angulo $P$ (2010) Long-term mortality in nonalcoholic fatty liver disease: is liver histology of any prognostic significance? Hepatology 51: 373-375

26. Marchesini G, Bugianesi E, Forlani G, Cerrelli F, Lenzi M, et al. (2003) Nonalcoholic fatty liver, steatohepatitis, and the metabolic syndrome. Hepatology 37: 917-923.

27. Prashanth M, Ganesh HK, Vima MV, John M, Bandgar T, et al. (2009) Prevalence of nonalcoholic fatty liver diease in patients with type 2 diabetes mellitus. J Assoc Physicians India 57: 205-210.

28. Kelley DE, McKolanis TM, Hegazi RA, Kuller LH, Kalhan SC (2003) Fatty liver in type 2 diabetes mellitus: relation to regional adiposity, fatty acids, and insulin resistance. Am J Physiol Endocrinol Metab 285: E906-916.

29. Meerwaldt R, Lutgers HL, Links TP, Graaff R, Baynes JW, et al. (2007) Skin autofluorescence is a strong predictor of cardiac mortality in diabetes. Diabetes Care 30: 107-112.

30. Takino J, Kobayashi $Y$, Takeuchi M (2010) The formation of intracellular glyceraldehyde-derived advanced glycation end-products and cytotoxicity. J Gastroenterol 45: 646-655.

31. Hyogo H, Yamagishi S, Iwamoto K, Arihiro K, Takeuchi M, et al. (2007) Elevated levels of serum advanced glycation end products in patients with non-alcoholic steatohepatitis. J Gastroenterol Hepatol 22: 1112-1119.

32. Targher G, Pichiri I, Zoppini G, Trombetta M, Bonora E, et al. (2012) Increased prevalence of chronic kidney disease in patients with Type 1 diabetes and nonalcoholic fatty liver. Diabet Med J Br Diabet Assoc 29: 220-226.

33. Friedrich-Rust M, Ong MF, Martens S, Sarrazin C, Bojunga J, et al. (2008) Performance of transient elastography for the staging of liver fibrosis: a metaanalysis. Gastroenterology 134: 960-974.

34. Sasso M, Miette V, Sandrin L, Beaugrand M (2012) The controlled attenuation parameter (CAP): a novel tool for the non-invasive evaluation of steatosis using Fibroscan. Clin Res Hepatol Gastroenterol 36: 13-20.

35. Chon YE, Jung KS, Kim SU, Park JY, Park YN, et al. (2014) Controlled attenuation parameter (CAP) for detection of hepatic steatosis in patients with chronic liver diseases: a prospective study of a native Korean population. Liver Int 34: 102-109. 